\title{
Role of Surgery in the Treatment of Oropharyngeal Squamous Cell Carcinoma: A Population-Based Review
}

\author{
Basem T. Jamal ${ }^{1^{*}}$ and Scharukh Jalisi ${ }^{2}$ \\ ${ }^{1}$ Consultant and Assistant Professor Oral \& Maxillofacial Surgery/Head and Neck Surgical Oncology, King AbdulAziz University, Jeddah, \\ Saudi Arabia
}

${ }^{2}$ Associate Professor Otolaryngology Head and Neck Surgery, Boston Medical Center, Boston, USA

Received: December 2, 2016; Accepted: January 30, 2017; Published:April 27, 2017

*Corresponding author: Basem T Jamal, Assistant Professor and Consultant Oral \& Maxillofacial Surgery/Head \& Neck Surgical Oncology, King AbdulAziz University Hospital, Jeddah, Saudi Arabia, Tel: +966-55559178; E-mail: bjamal@kau.edu.sa

\section{Abstract}

Background: Since most oropharyngeal carcinomas are locally advanced at presentation, patients are often treated with radiation therapy and/or chemotherapy. However, for early stage oropharyngeal carcinoma, national guidelines state that it can be treated by either primary surgery or radiotherapy. This study analyse national survival rates of oropharyngeal squamous cell carcinoma for surgical and nonsurgical treatment modalities.

Methods: All cases of squamous cell carcinoma of the oropharynx between 1988 and 2007 were selected from the Surveillance, Epidemiology and End Results (SEER) 17 database. The SEER database is a population-based cancer registry that captures 17 distinct population groups in 198 counties in the United States. It represents approximately $26 \%$ of the overall United States population and contains information on $6,117,327$ cases of cancer diagnosed since 1973. Overall survival was the primary outcome measure. Survival curves were generated using the Kaplan-Meier method and compared using the Mantel-Cox log-rank test. Significance was defined as $\mathrm{P}<0.05$.

Results: A total of 24,980 patients with squamous cell carcinoma of the oropharynx diagnosed from 1988 to 2007 were analysed. For Stages I \&II Post-op RT yielded better survival than Pre-op RT (P $=0.0096$, Hazard ratio $=1.464,95 \%$ $\mathrm{CI}=1.097$ to 1.954$)$. However, for Stages III\&IV There was no difference in survival between the pre-op RT and post-op RT groups $(\mathrm{P}=0.4099$; hazard ratio $=0.9518 ; 95 \% \mathrm{CI}=0.8464$ to 1.070).

Conclusion: These data suggest that for early stage oropharyngeal carcinomas, surgery yields better survival rates than radiotherapy alone. Hence, the authors advocate surgery as the first option in these tumors if clear margins can be achieved, allowing radiotherapy to be preserved for locoregional failures or second primary tumors.

Keywords: Oropharyngeal; Radiation; Surgery; SEER

\section{Background}

Head and neck squamous cell carcinoma is the sixth most common malignancy worldwide, with the oropharynx being the third most commonly affected site. The oropharynx consists of multiple subunits, and the tonsil is the most commonly affected structure within the oropharynx $[1,2]$.

The incidence of oral cancer has been decreasing in developed countries over the past few decades because of decreased use of tobacco. However, the incidence of oropharyngeal squamous cell carcinoma (OPSCC), likely developing secondary to HPV infection, has increased dramatically.[3,4]At least $70 \%$ of OPSCCs in the U.S. in recent years are thought to be caused by HPV infection, compared to $16.3 \%$ in 1984-1989, and fewer than $10 \%$ currently in less economically developed countries $[3,5]$. OPSCC presents with odynophagia, otalgia, bleeding, trismus, and constitutional complaints of weight loss, night sweats, and weakness. It predominantly occurs in males, with a male-to-female incidence ratio ranging from 3:1 to $4: 1$, and presents in the fifth decade of life or later $[1,2]$.

The management of OPSCC is the based on myriad advances in surgical, medical, and radiation oncology. Primary concurrent chemotherapy and radiation therapy (RT) remains the primary method for treating advanced OPSCC, regardless of whether it is HPV-positive or -negative. Surgery is often reserved as salvage treatment for cases with local or regional recurrence, but it carries a significant risk of complications and disfigurement.

Early interest in the combined use of chemotherapy and RT was stimulated by the landmark Veterans Affairs and European Organization for Research and Treatment of Cancer studies. Both these studies compared the efficacy of chemoradiotherapy (CRT) with that of primary surgery in patients with cancers of the larynx and hypopharynx $[1,2,6,7]$.

However, CRT is not without associated morbidity and risk, and advances in surgical techniques and approaches have proved invaluable in the management of advanced OPSCC. Importantly, recent studies have illustrated the accuracy of operative staging and the direct impact of surgical findings on subsequent adjuvant therapy $[8,9]$. Because the goal of cancer treatment is to maximize treatment effectiveness, while minimizing treatment- 
associated morbidity, there has been a renewed interest in the role of primary surgery in oropharyngeal carcinoma. A recent randomized clinical trial with long-term follow-up performed by Lyer et al. revealed that treatment outcome and overall survival after CRT did not significantly differ from that after primary surgery with adjuvant RT, although a slight advantage was observed in the surgery with adjuvant RT arm [10].

The purpose of this study was to utilize population-data collected from the Surveillance, Epidemiology, and End Results (SEER) database to provide novel insight into the role of primary surgery in the treatment of OPSCC, and to compare this role with its current role as salvage therapy.

\section{Methods}

The Surveillance, Epidemiology, and End Results (SEER) Program is a population-based cancer registry that includes 17 distinct population groups in 198 counties in the United States. It represents approximately $26 \%$ of the overall United States population and contains information on over 6 million cases of cancer diagnosed since 1973 [11].

All patients with OPSCC that was newly diagnosed between 1988 and 2007 were selected from the SEER database. The International Classification of Diseases for Oncology (3rd revision) was used to select patients with OPSCC (site codes: C01.9, C02.4, C05.1, C05.2, C09.0, C09.1, C09.9, C10.0, C10.2, C10.3, C10.9, and C14.2)

Data collected included patient age, TNM staging, treatment rendered, sequence of radiation in relation to surgery, number of head and neck primary tumors, cause of death, and overall survival. American Joint Committee on Cancer (AJCC) T, N, and M stage were recorded (according to the 6th edition of the AJCC Cancer Staging Manual) for patients diagnosed after 2003 [12]. Patients diagnosed in or before 2003 were manually classified using the 6th edition $\mathrm{T}, \mathrm{N}$, and $\mathrm{M}$ staging based on extent of disease variables obtained from the SEER database. We excluded patients for whom staging and timing of RT relative to surgery could not be determined.

Overall survival was the primary outcome measure. Survival curves were generated using the Kaplan-Meier method and compared using the Mantel-Cox log-rank test. Significance was defined as $\mathrm{P}<0.05$.

\section{Results}

We analyzed 24,980 patients with OPSCC diagnosed between 1988 and 2007. For early OPSCC (stages I and II), the overall survival in patients who underwent surgery first followed by subsequent RT was better than that in patients who needed salvage surgery after RT treatment $(\mathrm{P}=0.0096$, hazard ratio $=$ $1.464,95 \%$ confidence interval $[\mathrm{CI}]=1.097$ to 1.954 ).

However, for advanced OPSCC (stages III and IV), there was no difference in survival between the two groups $(\mathrm{P}=0.4099$; hazard ratio $=0.9518 ; 95 \% \mathrm{CI}=0.8464$ to 1.070 )

Achi square test with Yates correction revealed that patients who had only one primary tumor were more likely to have received RT as part of their treatment than patients who developed multiple primary tumors $(\mathrm{P}<0.0001)$. Thus, the incidence of second primary tumors was significantly higher in the cohort of patients who underwent surgery only for OPSCC treatment and this difference was observed for both early and advanced stages of the disease.

\section{Discussion}

CRT, including intensity-modulated RT, is by no means a panacea, and long-term complications of RT can be significant. RT-related morbidity ranges from xerostomia, dysphagia, speech impairment, and dental dysfunction to severe subcutaneous fibrosis and carotid rupture $[13,14]$. Adverse effects of conventionally utilized chemotherapy include ototoxicity, nephrotoxicity, neurotoxicity, cardiac toxicity, and loss of reproductive capability [15 $-18,13]$. In addition, both radiotherapy and chemotherapy can increase the risk of secondary cancers in long-term survivors, [19] and incomplete response to definitive CRT can necessitate potentially disfiguring salvage surgery. However, few studies have investigated the use of surgery or chemotherapy as a single modality, even though surgery is often used as the initial treatment with or without adjuvant RT. Definitive radiation therapy or surgical resection are currently considered in the management of early stage oropharyngeal tumors. Concurrent chemoradiation are considered for locally advanced resectable disease and advanced regional disease and indicated as postoperative adjuvant therapy in the presence of high-risk features such as extracapsular nodal spread and/or positive surgical margins, and can be considered in other circumstances.

The prognosis in patients with HPV-positive tumorsis significantly better than that in patients with HPV-negative disease, with a consistent $60-80 \%$ reduction in mortality in the former cases [2, 20 -31]. Licitra et al. showed that the four-year overall survival in patients with HPV-positive OPSCC was almost twice that in patients with HPV-negative OPSCC after primarily surgical treatment [32]. Thus, HPV-positive OPSCC has been identified as a specific disease entity with improved response to therapy. Therefore, the implementation of surgical approaches, especially transoral minimally invasive ones, along with the de-escalation of CRT in order to improve functional outcomes and reduce complications is the future direction of OPSCC treatment and many studies have focused on this approach over the past decade [33 - 35].

Our data suggest that patients who underwent surgery for early stage OPSCC prior to RT had a statistically significant survival advantage over patients who underwent salvage surgery after RT treatment. While this finding was not replicated in patients with advanced stage tumors, an important factor to consider is the availability of RT centers in different regions of the world to enable patients to receive timely and uninterrupted treatment. Many reports indicate that the availability of RT centers in the Middle East, including Saudi Arabia, is limited. In this region, approximately 2-3 million individuals are served by one radiation center, whereas the accepted limit is less than 500,000 individuals per center.36Excessive time between disease onset and initiation of RT increases the risk of local tumor recurrence and eventual treatment failure [33, 37]. Many studies have also shown that interruptions and delay in the initiation of RT can be detrimental to patient treatment outcome and survival [38, 39]. 
A benefit of surgical approaches is the ability to accurately stage the patient histologically and identify the presence of high-risk histologic features, so that appropriate adjuvant therapy can be selected and the radiation dose can consequently be reduced [40, 33 - 35]. Some patients might not even need RT because down stagingis relatively common following surgical intervention, with a decrease in stage after resection occurring in almost $31 \%$ of one cohort in a previous study [8].

In addition to the reduced burden on RT centers, a surgical approach can also potentially decrease the side effects of adjuvant RT, and thereby significantly improve the patients' quality of life measures. RT and age greater than 55 years are associated with a negative effect on factors implicated in quality of life, specifically speech and swallowing functions, and aesthetic appearance $[41,42]$. RT has been identified as a factor that negatively affects quality of life measures in other studies as well.

\section{Conclusion}

We advise the implementation of minimally invasive surgical approaches as primary treatment of both early and advanced stages of OPSCC in countries and regions with limited availability of RT. Several studies have indicated a favorable role for surgery in this cohort of patients and have highlighted its potential to reduce the burden on RT centers and reduce the subsequent delays in patient treatment.

\section{Declarations}

Ethics approval: The study design was approved by the appropriate ethics review board

Availability of data: The datasets generated during the current study are available in the Surveillance, Epidemiology and End Results (SEER) database and was analysed according to the parameters described in the methods

Competing Interest and Funding: both authors have no competing interest and no conflicts of interest to declare and there was no funding for this study

Author's contribution: BJ and SJ formulated the study question and design and selected the data. BJ analysed and interpreted the data. BJ and SJ contributed to the writing and reviewing of the manuscript.

\section{References}

1. American Cancer Society. Oral Cavity and Oropharyngeal Cancer. Accessed. 2015. Available from: http://www.cancer.org/acs/groups/ cid/documents/webcontent/003128-pdf.pdf.

2. Ang KK, Harris J, Wheeler R, Weber R, Rosenthal DI, Nguyen-Tân PF et al. Human papillomavirus and survival of patients with oropharyngeal cancer. N Engl J Med. 2010;363(1):24-35. doi: 10.1056/NEJMoa0912217.

3. Chaturvedi AK, Anderson WF, Lortet-Tieulent J, Paula Curado M, Ferlay J, Franceschi S, et al. Worldwide trends in incidence rates for oral cavity and oropharyngeal cancers. J Clin Oncol. 2013;31(36):4550-4559. doi: $10.1200 / J C 0.2013 .50 .3870$

4. Simard EP, Torre L a., Jemal A. International trends in head and neck cancer incidence rates: Differences by country, sex and anatomic site. Oral Oncol. 2014;50(5):387-403. doi: 10.1016/j.oraloncology.2014.01.016.
5. Pytynia KB, Dahlstrom KR, Sturgis EM. Epidemiology of HPV-associated oropharyngeal cancer. Oral Oncol. 2014;50(5):380-386.

6. Ziegler EJ. Induction Chemotherapy plus Radiation Compared with Surgery plus Radiation in Patients with Advanced Laryngeal Cancer. N Engl J Med. 1991;324(24):1685-1690.

7. Lefebvre JL, Chevalier D, Luboinski B, Kirkpatrick A, Collette L, Sahmoud T. Larynx preservation in pyriform sinus cancer: preliminary results of a European Organization for Research and Treatment of Cancer phase III trial. EORTC Head and Neck Cancer Cooperative Group. J Natl Cancer Inst. 199;88(13):890-899.

8. Haughey BH, Sinha P. Prognostic factors and survival unique to surgically treated p16+ oropharyngeal cancer. Laryngoscope. 2012;S1333. doi: 10.1002/lary.23493.

9. Shah S, Goldenberg D. Robotic surgery for oropharyngeal cancer. Rambam Maimonides Med J. 2014;5(2):e0014. doi: 10.5041/RMMJ.10148.

10. Iyer NG, Tan DSW, Tan VKM, Wang W, Hwang J, Tan N-C, et al. Randomized trial comparing surgery and adjuvant radiotherapy versus concurrent chemoradiotherapy in patients with advanced, nonmetastatic squamous cell carcinoma of the head and neck: 10-year update and subset analysis. Cancer. 2015;121(10):1599-1607. doi: 10.1002/ cncr.29251.

11. National Cancer Institute. SEER brochur. NIH Publication 05-4772. 2005. Available from: https://seer.cancer.gov/about/factsheets/ SEER_brochure.pdf

12. American Joint Committee on Cancer. AJCC Cancer Staging Manual. 6th ed. New York: Springer; 2002.

13. Janot F, de Raucourt D, Benhamou E, Ferron C, Dolivet G, Bensadoun R-J, et al. Randomized trial of postoperative reirradiation combined with chemotherapy after salvage surgery compared with salvage surgery alone in head and neck carcinoma. J Clin Oncol. 2008;26(34):55185523. doi: 10.1200/JC0.2007.15.0102.

14. Lee N, Chan K, Bekelman JE, Zhung J, Mechalakos J, Narayana A, et al. Salvage re-irradiation for recurrent head and neck cancer. Int J Radiat Oncol Biol Phys. 2007;68(3):731-740.

15. Meinardi MT, Gietema JA, van der Graaf WT, van Veldhuisen DJ, Runne MA, Sluiter WJ, et al. Cardiovascular morbidity in long-term survivors of metastatic testicular cancer. J Clin Oncol. 2000;18(8):1725-1732.

16. Pala M, Odrazka K, Holeckova P, Vitek P, Kubes J, Dvorak J, et al. Definitive radiochemotherapy with weekly cisplatin in patients with head and neck cancer; single institution outcome analysis. J BUON. 2012;17(3):471-477.

17. Strumberg D, Brügge S, Korn MW, Koeppen S, Ranft J, Scheiber G, et al. Evaluation of long-term toxicity in patients after cisplatin-based chemotherapy for non-seminomatous testicular cancer. Ann Oncol. 2002;13(2):229-236.

18. Hitchcock YJ, Tward JD, Szabo A, Bentz BG, Shrieve DC. Relative contributions of radiation and cisplatin-based chemotherapy to sensorineural hearing loss in head-and-neck cancer patients. Int J Radiat Oncol Biol Phys. 2009;73(3):779-788. doi: 10.1016/j.ijrobp.2008.05.040.

19. Van den Belt-Dusebout AW, de Wit R, Gietema JA, Horenblas S, Louwman MWJ, Ribot JG, et al. Treatment-specific risks of second malignancies and cardiovascular disease in 5-year survivors of testicular cancer. J Clin Oncol. 2007;25(28):4370-4378.

20. Fakhry C, Westra WH, Li S, Cmelak A, Ridge JA, Pinto H, et al. Improved survival of patients with human papillomavirus-positive head and neck squamous cell carcinoma in a prospective clinical trial. J Natl Cancer Inst. 2008;100(4):261-269. doi: 10.1093/jnci/djn011.

21. Sedaghat AR, Zhang Z, Begum S, Palermo R, Best S, Ulmer KM, et al. Prognostic significance of human papillomavirus in oropharyngeal squamous cell carcinomas. Laryngoscope. 2009;119(8):1542-1549. doi: 10.1002/lary.20533.

22. Nichols AC, Faquin WC, Westra WH, Mroz EA, Begum S, Clark JR, et al. HPV-16 infection predicts treatment outcome in oropharyngeal squamous cell carcinoma. Otolaryngol Head Neck Surg. 2009;140(2):228324. doi: 10.1016/j.otohns.2008.11.025. 
23. Schwartz SR, Yueh B, McDougall JK, Daling JR, Schwartz SM. Human papillomavirus infection and survival in oral squamous cell cancer: a population-based study. Otolaryngol Head Neck Surg. 2001;125(1):19.

24. Weinberger PM, Yu Z, Haffty BG, Kowalski D, Harigopal M, Sasaki C, et al. Prognostic significance of p16 protein levels in oropharyngeal squamous cell cancer. Clin Cancer Res. 2004;10(17):5684-5691.

25. Mellin H, Friesland S, Lewensohn R, Dalianis T, Munck-Wikland E. Human papillomavirus (HPV) DNA in tonsillar cancer: clinical correlates, risk of relapse, and survival. Int J cancer. 2000;89(3):300-304

26. Gillison ML, Koch WM, Capone RB, Spafford M, Westra WH, Wu L, et al. Evidence for a causal association between human papillomavirus and a subset of head and neck cancers. J Natl Cancer Inst. 2000;92(9):709720

27. Lindel K, Beer KT, Laissue J, Greiner RH, Aebersold DM. Human papillomavirus positive squamous cell carcinoma of the oropharynx: a radiosensitive subgroup of head and neck carcinoma. Cancer 2001;92(4):805-813.

28. Ragin CCR, Taioli E. Survival of squamous cell carcinoma of the head and neck in relation to human papillomavirus infection: review and meta-analysis. Int J cancer. 2007;121(8):1813-1820.

29. Rischin D, Young RJ, Fisher R, Fox SB, Le Q-T, Peters LJ, et al. Prognostic significance of p16INK4A and human papillomavirus in patients with oropharyngeal cancer treated on TROG 02.02 phase III trial. J Clin Oncol. 2010;28(27):4142-4148. doi: 10.1200/JC0.2010.29.2904.

30. Posner MR, Lorch JH, Goloubeva O, Tan M, Schumaker LM, Sarlis NJ, et al. Survival and human papillomavirus in oropharynx cancer in TAX 324: a subset analysis from an international phase III trial. Ann Oncol 2011;22(5):1071-1077. doi: 10.1093/annonc/mdr006.

31. Lassen P, Eriksen JG, Krogdahl A, Therkildsen MH, Ulhøi BP, Overgaard $\mathrm{M}$, et al. The influence of HPV-associated p16-expression on accelerated fractionated radiotherapy in head and neck cancer: Evaluation of the randomised DAHANCA 6\&7 trial. Radiother Oncol. 2011;100(1):49-55. doi: 10.1016/j.radonc.2011.02.010.

32. Licitra L, Perrone F, Bossi P, Suardi S, Mariani L, Artusi R, et al. Highrisk human papillomavirus affects prognosis in patients with surgically treated oropharyngeal squamous cell carcinoma. J Clin Oncol. 2006;24(36):5630-5636.
33. Feng FY, Kim HM, Lyden TH, Haxer MJ, Feng M, Worden FP, et al. Intensity-modulated radiotherapy of head and neck cancer aiming to reduce dysphagia: early dose-effect relationships for the swallowing structures. Int J Radiat Oncol Biol Phys. 2007;68(5):1289-1298.

34. Rancati T, Schwarz M, Allen AM, Feng F, Popovtzer A, Mittal B, et al. Radiation dose-volume effects in the larynx and pharynx. Int J Radiat Oncol Biol Phys. 2010;76(3 Suppl):S64-9.

35. Smith R V, Goldman SY, Beitler JJ, Wadler SS. Decreased short- and long-term swallowing problems with altered radiotherapy dosing used in an organ-sparing protocol for advanced pharyngeal carcinoma. Arch Otolaryngol Head Neck Surg. 2004;130(7):831-836.

36. International Atomic Energy Agency (IAEA) Human Health. International Atomic Energy Agency (IAEA) Human Health Series No. 14. Planning National Radiotherapy Services: A Practical Tool. International Atomic Energy Agency, 2010. 2010.

37. Chen Z, King W, Pearcey R, Kerba M, Mackillop WJ. The relationship between waiting time for radiotherapy and clinical outcomes: a systematic review of the literature. Radiother Oncol. 2008;87(1):3-16.

38. Allal AS, de Pree C, Dulguerov P, Bieri S, Maire D, Kurtz JM. Avoidance of treatment interruption: an unrecognized benefit of accelerated radiotherapy in oropharyngeal carcinomas? Int J Radiat Oncol. 1999;45(1):41-45

39. Ang KK, Trotti A, Brown BW, Garden AS, Foote RL, Morrison WH, et al. Randomized trial addressing risk features and time factors of surgery plus radiotherapy in advanced head-and-neck cancer. Int J Radiat Oncol Biol Phys. 2001;51(3):571-578.

40. Mydlarz WK, Chan JYK, Richmon JD. The role of surgery for HPV-associated head and neck cancer. Oral Oncol. 2015;51(4):305-313.

41. Dziegielewski PT, Teknos TN, Durmus K, Old M, Agrawal A, Kakarala K, et al. Transoral robotic surgery for oropharyngeal cancer: long-term quality of life and functional outcomes. JAMA Otolaryngol Head Neck Surg. 2013;139(11):1099-1108.

42. Leonhardt FD, Quon H, Abrahão M, O'Malley BW, Weinstein GS. Transoral robotic surgery for oropharyngeal carcinoma and its impact on patient-reported quality of life and function. Head Neck. 2012;34(2):146-154. doi: 10.1002/hed.21688. 